\title{
Simple method for culture of peripheral blood lymphocytes of Testudinidae
}

\author{
T.L. Silva, M.I.A. Silva, L.P.R. Venancio, C.E.S. Zago, V.A.G. Moscheta, \\ A.V.B. Lima, L.D. Vizotto, J.R. Santos, C.R. Bonini-Domingos and \\ M.T.V. Azeredo-Oliveira \\ Departamento de Biologia, Centro de Estudos de Quelônios, \\ Instituto de Biociências, Letras e Ciências Exatas, \\ Universidade Estadual Paulista "Júlio de Mesquita Filho", \\ São José do Rio Preto, SP, Brasil \\ Corresponding author: T.L. Silva \\ E-mail: lucenabio@hotmail.com
}

Genet. Mol. Res. 10 (4): 3020-3025 (2011)

Received December 10, 2010

Accepted March 25, 2011

Published December 6, 2011

DOI http://dx.doi.org/10.4238/2011.December.6.2

\begin{abstract}
We developed and optimized a simple, efficient and inexpensive method for in vitro culture of peripheral blood lymphocytes from the Brazilian tortoise Chelonoidis carbonaria (Testudinidae), testing various parameters, including culture medium, mitogen concentration, mitotic index, culture volume, incubation time, and mitotic arrest. Peripheral blood samples were obtained from the costal vein of four couples. The conditions that gave a good mitotic index were lymphocytes cultured at $37^{\circ} \mathrm{C}$ in minimum essential medium $(7.5 \mathrm{~mL})$, with phytohemagglutinin as a mitogen $(0.375 \mathrm{~mL})$, plus streptomycin/penicillin $(0.1 \mathrm{~mL})$, and an incubation period of $72 \mathrm{~h}$. Mitotic arrest was induced by $2-\mathrm{h}$ exposure to colchicine $(0.1 \mathrm{~mL}), 70 \mathrm{~h}$ after establishing the culture. After mitotic arrest, the cells were hypotonized with 0.075 $\mathrm{M} \mathrm{KCl}$ for $2 \mathrm{~h}$ and fixed with methanol/acetic acid (3:1). The nonbanded mitotic chromosomes were visualized by Giemsa staining. The diploid chromosome number of $C$. carbonaria was found to be 52 in females and males, and sex chromosomes were not observed. We were
\end{abstract}


able to culture peripheral blood lymphocytes of a Brazilian tortoise in vitro, for the preparation of mitotic chromosomes.

Key words: Testudinidae; Chelonoidis carbonaria; Cytogenetic; Lymphocyte culture

\section{INTRODUCTION}

Cytogenetic identification is an important parameter for the organism's identification in their natural habitat. The first level of genome analysis involves karyotyping of mitotic chromosomes to determine the organism's genome organization at the cytological level (Singh et al., 1970; Gormam, 1973). The classical methods of chromosome preparation in whole animals involve killing the study specimen or using surgical procedures that are often unsafe for survival of the animal, traumatic and unethical, because in vivo inoculation with colchicine solution is required. After killing, cells can be obtained from the spleen, lung, kidney (Medrano et al., 1987) or spinal cord (Kamesaki, 1989). These cells are cultured and stimulated to obtain metaphases (Bickham, 1975; Killebrew, 1975; Bickham and Baker, 1976; Bickham and Carr, 1980, 1983; Medrano et al., 1987; Kamezaki, 1989, 1990). These methods are generally not feasible in endangered species, because of the risk and number of animals available. In such cases, karyotype analysis using cultured blood lymphocytes without animal sacrificing is most desirable and useful. Few reports are available for lymphocyte cultures of tortoises (Maecha, 1998; Ulsh et al., 2000a; Ortiz and Rodríguez, 2003), but the methods previously described did not show satisfactory results, because of cells' differential adaptability, variation in preferred body temperature, lymphocyte population, and immunological responses to mitogen stimulation.

The genus Chelonoidis (Fitzinger, 1835) is currently represented by four species in South America: Chelonoidis carbonaria, C. denticulata, C. chilensis, and C. nigra. The species $C$. carbonaria is considered to be endangered according to the Convention on International Trade in Endangered Species of Wild Fauna and Flora (IUCN, 2004), which may become extinct if illegal trade and habitat loss are not controlled. C. carbonaria occurs in dry forests and areas of forest vegetation in savannas.

We determined the requirements for the growth of peripheral blood cells of $C$. carbonaria, to obtain metaphases and generate information about the karyotypic characteristics of this species, providing the basis for future research in the cytogenetics of this species.

\section{MATERIAL AND METHODS}

Experiments were carried out on 8 adult individuals of $C$. carbonaria from the "Reginaldo Uvo Leone" breeding farm in Tabapuã, São Paulo, Brazil (2059'47.4"S, $\left.49^{\circ} 07^{\prime} 16.6^{\prime \prime} \mathrm{W}\right)$. The animal care procedures followed in this study were authorized by the Comissão de Ética em Experimentação Animal (CEEA) of the Universidade Estadual Paulista "Júlio de Mesquita Filho", UNESP/IBILCE (No. 018/09) and approved by IBAMA/ SISBIO (No. 19514-1).

A total of 20 experiments were carried out at the Centro de Estudos de Quelônios (CEQ), Universidade Estadual Paulista "Júlio de Mesquita Filho", to determine the conditions 
needed to obtain a good mitotic index, such as volume of culture medium, concentrations of phytohemagglutinin and fetal bovine serum and lymphocyte layer volume. We also determined the optimal times for incubation, mitotic arrest and hypotonization (data not shown).

The costal vein, located lateral to the longitudinal axis of the animal, was used as the blood sampling site, which was first cleaned with distilled water and $70 \%$ ethanol (Silva et al., 2011).

About $5 \mathrm{~mL}$ blood was collected from each animal. The samples were immediately transferred to sterilized tubes containing heparin and stored at $37^{\circ} \mathrm{C}$ for $2 \mathrm{~h}$. After blood collection, the skin was again swabbed with $70 \%$ ethanol to prevent microbial infection. The animals were kept under observation to assure recovery before being released. Cell types such as red blood cells and lymphocytes were separated in a centrifuge tube according to their density. The upper layer lymphocytes were transferred to a sterile centrifuge tube, and incubated at $37^{\circ} \mathrm{C}$ for complete separation of lymphocytes.

First, $7.5 \mathrm{~mL}$ MEM culture medium was placed in a $15-\mathrm{mL}$ Falcon tube. All other components were added serially (see Table 1). These steps were carried out in sterile conditions in a laminar flow hood to avoid microbial contamination. The total volumes used per sample are shown in Table 1.

\begin{tabular}{lc} 
Table 1. Components of short-term culture of peripheral blood lymphocytes of Chelonoidis carbonaria. \\
\hline Component & Culture volume \\
\hline MEM (E) with $\mathrm{NaHCO}_{3}$ (CULTILAB) & $7.5 \mathrm{~mL}$ \\
Penicillin-streptomycin (10,000 IU/mL-10 mg/mL) & $0.1 \mathrm{~mL}$ \\
PHA-P (CULTILAB) & $0.375 \mathrm{~mL}$ \\
Fetal bovine serum (CULTILAB) & $1.5 \mathrm{~mL}$ \\
Lymphocytes with serum (separated from $5 \mathrm{~mL}$ whole blood) & $2.0 \mathrm{~mL}$ \\
Colchicine (16 $\mu \mathrm{g} / \mathrm{mL})$ & $0.1 \mathrm{~mL}$ \\
\hline
\end{tabular}

The culture was placed in an incubator set at $37^{\circ} \mathrm{C}$, and shaken gently every morning to break up cell clumps. After $70 \mathrm{~h}$ of incubation, $0.1 \mathrm{~mL}$ colchicine was added to a final concentration of $16 \mu \mathrm{g} / \mathrm{mL}$, and the cells were harvested after $2 \mathrm{~h}$ for a good mitotic count (Ulsh et al., 2000a, adapted).

The cells were centrifuged at $900 \mathrm{rpm}$ for $5 \mathrm{~min}$. After discarding the supernatant, the cell pellet was resuspended in a hypotonic solution $(1 \mathrm{~mL}$ pre-warmed $0.075 \mathrm{M} \mathrm{KCl})$ and the cells incubated at $37^{\circ} \mathrm{C}$, for $2 \mathrm{~h}$. At the end of hypotonic treatment, a few drops of fixative solution (one part glacial acetic acid and three parts absolute methanol) were added to the hypotonic solution to prefix the cells, followed by centrifugation at $900 \mathrm{rpm}$ for $5 \mathrm{~min}$. Again, after discarding the supernatant, the cell pellet was resuspended in $1 \mathrm{~mL}$ freshly prepared glacial acetic acid-methanol following gentle mixing. The last step (fixation) was repeated twice for proper fixation. The cells were finally suspended in $0.5 \mathrm{~mL}$ fixative solution for chromosome preparation.

Chromosomes were prepared by the splash technique (Ulsh et al., 2000b), stained with 6\% Giemsa prepared in Sorenson's buffer (Ulsh et al., 2000a), air-dried, and kept in the refrigerator for proper storage. Chromosomes from at least 20 metaphases were counted and the best mitotic spreads were photographed using a light microscope equipped with an image analyzer (AXIOCAM ${ }^{\circledR}$ ICc 3). 
Chromosomes were identified according to Bickham (1975) and arranged in three groups: Group A, consisting of large-size macrochromosomes; Group B consisting of mediumsize macrochromosomes, and Group $\mathrm{C}$, including all the microchromosomes whose centromeric position was not clearly identifiable.

\section{RESULTS AND DISCUSSION}

In this study, the best conditions to obtain a high mitotic index were: MEM culture media $(7.5 \mathrm{~mL} /$ sample) combined with phytohemagglutinin $(0.375 \mu \mathrm{L} / \mathrm{sample})$, fetal bovine serum ( $1.5 \mathrm{~mL} / \mathrm{sample})$, and $2 \mathrm{~mL}$ lymphocyte layer. The cultures were placed in an incubator at $37^{\circ} \mathrm{C}$. After $70 \mathrm{~h}, 0.1 \mathrm{~mL}$ colchicine was added, and after further incubation for $2 \mathrm{~h}$, the cells were suspended in $0.075 \mathrm{M} \mathrm{KCl}$ for $2 \mathrm{~h}$. Methanol-acetic acid (3:1) was used as the fixative. The mitotic cells were collected after $72 \mathrm{~h}$.

With the method described above, metaphases were identified with a good distribution and number, allowing the identification of sets of chromosomes. The non-banded mitotic chromosomes were visualized by Giemsa staining. Chelonoidis carbonaria revealed a diploid number of $2 \mathrm{n}=52$ chromosomes, in both sexes, divided into three groups (A, B, C). Group A was composed of 28 chromosomes ( 3 metacentric pairs, one acrocentric and 10 submetacentric pairs), group $\mathrm{B}$ consisted of seven pairs of acrocentric chromosomes, and group $\mathrm{C}$ showed five pairs of microchromosomes (Figure 1A,B). Sex chromosomes were not observed.

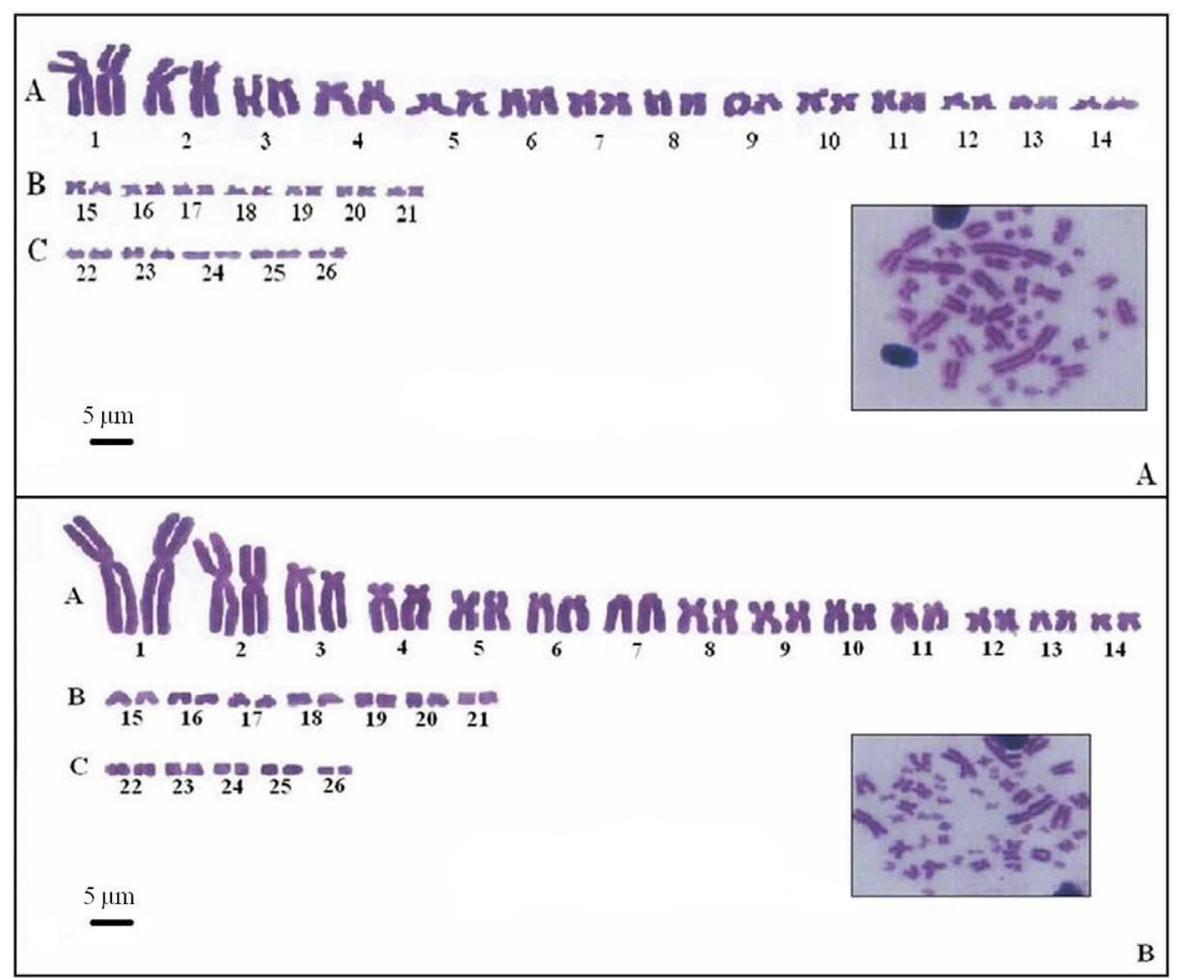

Figure 1. Karyogram of Chelonoidis carbonaria by Giemsa staining. A. Female. B. Male. Bar $=5 \mu \mathrm{m}$. 
The optimized conditions in this study yielded a good mitotic index of about 10-15 metaphases per slide. Our method showed better results for Testudinidis than those methods described for mammals, including humans and also for other reptiles, resulting in good mitotic index (Ulsh et al., 2000a; Ciofi et al., 2002). The culture technique we optimized can be applied to other tortoise species, also with certain modifications in essential parameters such as incubation temperature, incubation period, serum concentration, and mitogen.

The diploid chromosome number $2 \mathrm{n}=52$ has been observed in other members of family Testudinidae, including $C$. denticulata, $C$. donosobarrosi, C. chilensis, C. elephantopus, and $C$. gigantea, and also in members of the families Pelomedusidae and Bataguridae (Forbes, 1966; Sampaio et al., 1971; Goldestein and Lin, 1972; Bickham, 1975; Bickham and Baker, 1976; Benirschke et al., 1976). Our data confirm that some species of the Testudinidae have a relatively smaller number of microchromosomes in relation to the family Trionychidae (Matsuda et al., 2005; Noleto et al., 2006; Rohilla et al., 2006). The mechanisms responsible for reducing the loss of microchromosomes can be numerical, translocation of microchromosomes to acrocentric chromosomes and formation of metacentric chromosomes during the evolution of Testudines (Bickham, 1975).

A simple, efficient and economic method was optimized for in vitro culture of peripheral blood lymphocytes from the Brazilian tortoise Chelonoidis carbonaria (Testudinidae), through the analysis of parameters including culture medium, mitogen concentration, mitotic index, culture volume, incubation time, duration of culture, and mitotic arrest. The present study was a successful attempt at in vitro culture of peripheral blood lymphocytes for the preparation of mitotic chromosomes for this species, and it is important because reveals a viable and economic protocol for Brazilian tortoise cell culture, without harming the animal. This protocol is particularly suited for a modestly equipped laboratory. These data may be useful for more accurate comparative cytogenetic studies regarding the karyotypic evolution in this group.

\section{ACKNOWLEDGMENTS}

Research supported by Fundação de Amparo à Pesquisa do Estado de São Paulo (FAPESP, Process \#2009/0446-9), Fundação para o Desenvolvimento da UNESP (FUNDUNESP, Process \#01098/07) and Conselho Nacional de Desenvolvimento Científico e Tecnológico (CNPq). We are also grateful to Reginaldo Uvo Leone for obtaining samples.

\section{REFERENCES}

Benirschke RJ, Quinn AD and Sekulovich RE (1976). Chromosomal studies in Geochelone (Testudinidae-Reptilia). Chromosome 12: 14-16.

Bickham JW (1975). A cytosystematic study of turtles in the genera Clemmys, Mauremys and Sacalia. Herpetologica 31: 198-204.

Bickham JW and Baker RJ (1976). Chromosome homology and evolution of emydid turtles. Chromosoma 54: 201-219.

Bickham JW and Carr JL (1980). The karyotype and chromosomal banding patterns of the green turtle (Chelonia mydas). Copeia 540-543.

Bickham JW and Carr JL (1983). Taxonomy and phylogeny of the higher categories of cryptodiran turtles based on a cladistic analysis of chromosomal data. Copeia 4: 918-932.

Ciofi C, Milinkovitch MC, Gibbs JP, Caccone A, et al. (2002). Microsatellite analysis of genetic divergence among populations of giant Galapagos tortoises. Mol. Ecol. 11: 2265-2283. 
Forbes WC Jr (1996). A Cytological Study of the Chelonia, Unpublished PhD Dissertation. University Connecticut, Storrs. Goldstein S and Lin CC (1972). Somatic cell hybrids between cultured fibroblasts from the Galapagos tortoise and the golden hamster. Exp. Cell Res. 73: 266-269.

Gorman GC (1973). The Chromosomes of the Reptilia, a Cytotaxonomic Interpretation. In: Cytotaxonomy of Vertebrate Evolution (Chiarelli AB and Capanna E, eds.). Academic Press, London, 349-424.

IUCN (2004). Red List of Threatened Species. Available at [http://www.iucnredlist.org]. Accessed December 15, 2010.

Kamesaki N (1989). Karyotypes of the loggerhead turtle, Caretta caretta, from Japan. Zool. Sci. 6: 421-422.

Kamesaki N (1990). Karyotype of the Haswkbill Turtle, Eretmochelys imbricata, from Japan, with notes on a method for preparation of chromosomes from liver cells. Jpn. J. Herpetol. 13: 111-113.

Killebrew FC (1975). Mitotic chromosomes of turtles: I. the Pelomedusidae. J. Herpetol. 9: 281-285.

Maecha S (1998). Caracterización Citogenética de Rhinoclemmys diademata (Mertens, 1954) (Testudina: Emididae). Trabajo de Grado, Universidad Nacional de Colombia, Facultad de Ciencias, Departamento de Biología, Bogotá.

Matsuda Y, Nishida-Umehara C, Tarui H, Kuroiwa A, et al. (2005). Highly conserved linkage homology between birds and turtles: bird and turtle chromosomes are precise counterparts of each other. Chromosome Res. 13: 601-615.

Medrano LM, Dorizzi F, Romblot C and Pieau C (1987). Karyotype of the sea turtle Demochelys coriacea (Vandelli, 1761). Amphibia-Reptilia 8: 171-178.

Noleto RB, Kantek DLZ and Swarça AC (2006). Karyotypic characterization of Hydromedusa tectifera (Testudines, Pleurodira) from the upper Iguaçu River in the Brazilian state of Paraná. Genet. Mol. Biol. 29: 263-266.

Ortiz M and Rodríguez P (2003). Estudio Citogenético de la Tortuga "Sabanera" (Podocnemis vogli. Müler, 1953) (Testudinata: Podocnemidae). Trabajo de Grado, Universidad Nacional de Colombia, Facultad de Ciencias, Departamento de Biología, Bogotá.

Rohilla MS, Rao RJ and Tiwari PK (2006). Use of peripheral blood lymphocyte culture in the karyological analysis of Indian freshwater turtles, Lissemys punctata and Geoclemys hamiltoni. Curr. Sci. 90: 1130-1134.

Sampaio MM, Barros RM, Ayres M and Cunha OR (1971). A karyological study of two species of tortoises from the Amazon Region of Brazil. Cytologia 36: 199-204.

Silva TL, Silva MIA, Venancio LPR, Zago CES, et al. (2011). Blood sampling in Testudinidae and Chelidae. Herpetol. Rev. (in press).

Singh L, Sharma T and Ray-Chaudhuri SP (1970). Chromosome numbers and sex chromosomes in few Indian species of amphibia and reptiles. Chromosome Newsl. 11: 91-94.

Ulsh BA, Congdon JD, Hinton TG, Whicker FW, et al. (2000a). Culture methods for turtle lymphocytes. Methods Cell Sci. 22: 285-297.

Ulsh BA, Muhlmann-Diaz MC, Whicker FW, Hinton TG, et al. (2000b). Chromosome translocations in turtles: a biomarker in a sentinel animal for ecological dosimetry. Radiat. Res. 153: 752-759. 